\title{
Anti-Corrosive Behavior of Ethanolic Extract of Banana Peel against Acidic Media and their Thermodynamic Studies
}

\author{
Dr. B. Senthilvadivu ${ }^{1}$, V. Aswini ${ }^{2}$, K. Santhosh Kumar ${ }^{3}$ \\ ${ }^{1}$ Assistant Professor, Department of Chemisty, Arignar Anna Government Arts College, Villupuram
}

\begin{abstract}
The anti-corrosion behaviour of banana peel extracts in $1 \mathrm{M} \mathrm{HCl}$ media on mild steel were studied using gravimetric method (weight loss method), electrochemical methods (electrochemical impedance spectroscopy (EIS) and potentiodynamic polarisation) and scanning electron microscope (SEM) techniques. The extracts were shown to have better inhibition efficiencies for the gravimetric and electrochemical methods. EIS analysis revealed that increase in concentration increases the charge transfer resistance, thus increased inhibition efficiency. The potentiodynamic polarisation measurements showed the extracts acted as mixed-type inhibitors with predominantly cathodic effectiveness. SEM techniques supported the achievement of corrosion inhibition with the presence of inhibitors. The adsorption mechanisms for peel extracts were mainly physisorption. Banana peel extract show better corrosion inhibition at lower concentration levels which can use for industrial applications.
\end{abstract}

\section{Introduction}

In most industries whose facilities are constituted by metallic structures, the phenomenon of corrosion is invariably present. This problem originates very important material and economic losses due to partial or total replacement of equipment and structures, and plant-repairing shutdowns. Material losses and corrosion consequences are priced so high that in some countries like the U.S. and England these factors have been estimated from 3 to $4 \%$ of the $\mathrm{GDP}^{1,2}$. Corrosion is the deterioration of materials by chemical interaction with their environment. The term corrosion is sometimes also applied to the degradation of plastics, concrete and wood, but generally refers to metals. In recent years, owing to the growing interest and attention of the world towards the protection of the environment and the hazardous effects of using chemicals on the ecological balance, the traditional approach on CIs has gradually changed $^{3}$. As mentioned before, for an inhibitor to be an effective protector against metal corrosion, it should be readily adsorbed on the metal surface through either physisorption or chemisorption processes. Either of these adsorption processes depends primarily on the physicochemical properties of the inhibitor group such as functional groups, electronic density at the donor atom, molecular structure, etc. For instance, organic molecules, which have had a wide applicability and that have been extensively studied and used as CIs, often contain nitrogen, oxygen, and sulphur atoms, as well as multiple bonds in their molecules.

Natural products have been studied extensively as corrosion inhibitors both in product mixtures extracted from natural sources such as plants or essentially pure products derived from animals or plants (i.e. vitamins and amino acids) ${ }^{4,5}$. From the economic and environmental viewpoints, plant extracts are an excellent alternative as inhibitors because of their availability and biodegradability. These extracts can be obtained in a simple way and purification methods are not required. The extracts are generally obtained from cheap solvents that are widely available, at a low cost and with low toxicity; the aqueous extract is more relieved, but due to the low solubility of many natural products in water, common ethanol extracts are also obtained ${ }^{6}$. These extracts contain a variety of natural products such as essential oils, tannins, pigments, steroids, terpenes, flavones and flavonoids, among other well-known active substances used as CIs. In general, these compounds present conjugated aromatic structures, long aliphatic chains such as nitrogen, sulphur, and oxygen heteroatoms with free electron pairs that are available to form bonds with the metal surface; in most cases, they act synergistically to exhibit good efficiency regarding the corrosion protection.

\section{1) Banana}

The banana is an edible fruit, botanically a berry, produced by several kinds of large herbaceous flowering plants in the genusMusa. ${ }^{7}$ In some countries, bananas used for cooking may be called plantains. The fruit is variable in size, color and firmness, but is usually elongated and curved, with soft flesh rich in starch covered with a rind which may be green, yellow, red, purple, or brown when ripe. The fruits grow in clusters hanging from the top of the plant ${ }^{8}$. Almost all modern edible parthenocarpic (seedless) bananas come from two wild species-Musa acuminata and Musa balbisiana. The scientific names of most cultivated bananas are Musa acuminata, Musa balbisiana, and Musa $\times$ paradisiaca for the hybrid Musa acuminata $\times$ M. balbisiana, depending on their genomic constitution. The old scientific name Musa sapientum is no longer used. Musa species are native to tropical Indomalaya and Australia, and are likely to have been first domesticated in Papua New Guinea. They are grown in at least 107 countries $^{9,10}$. Primarily for their fruit, and to a lesser extent to make fiber, banana wine and banana beer and as ornamental plants. Worldwide, there is no sharp distinction between "bananas" and "plantains". Especially in the Americas and Europe, "banana" usually refers to soft, sweet, dessert bananas, particularly those of the Cavendish group, which are the main exports from banana-growing countries. By contrast, Musa cultivars with firmer, starchier fruit are called "plantains". In other regions, such as Southeast Asia, many more kinds of banana are grown and eaten, so the simple two-fold distinction is not useful and is not made in local languages. The term "banana" is 


\section{International Journal of Science and Research (IJSR) \\ ISSN (Online): 2319-7064}

Index Copernicus Value (2015): 78.96 | Impact Factor (2015): 6.391

also used as the common name for the plants which produce the fruit $^{11}$. This can extend to other members of the genus Musa like the scarlet banana(Musa coccinea), pink banana (Musa velutina) and the Fe'i bananas. It can also refer to members of the genus Ensete, like the snow banana (Ensete glaucum) and the economically important false banana (Ensete ventricosum). Both genera are classified under the banana family, Musaceae.

\section{Experimental Methods}

\subsection{Preparation of aqueous extraction of Banana peel (BE)}

Banana fruit was purchased from local market. Banana peels were taken and then dried at room temperature for 1 week and was further dried in an oven for 24 hours. Dried sample was made into a fine powder. Dried sample of 50 grams was refluxed at $60^{\circ} \mathrm{c}$ for 8 hours using $150 \mathrm{ml}$ of Ethyl Alcohol $\left(\mathrm{C}_{2} \mathrm{H}_{5} \mathrm{OH}\right)$ as solvent. Solution of ethanolic Banana peel extract was separated from the peels using filter paper. Rotary evaporator at reduced pressure is used for the separation of ethyl alcohol and the Banana peel extract.

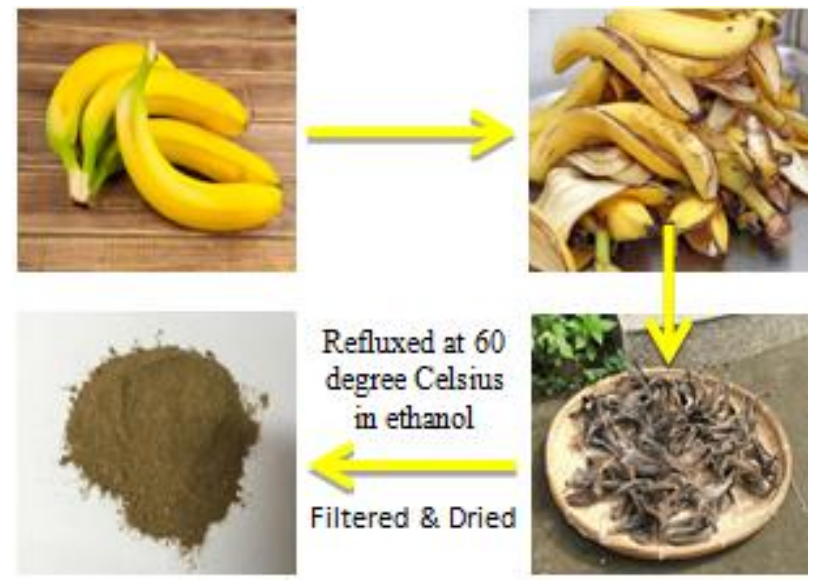

Figure 1: Extraction of banana peel

\subsection{Analysis of Chemical Constituents}

Fourier Transform Infrared Spectroscopy

The ethanolic extract of Banana peel were screened using the FT-IR (Schimadi-IR affinity). The spectra were recorded in the range of 4000 to $400 \mathrm{~cm}^{-1}$ and analysed for characteristic functional groups responsible for corrosion inhibition.

\section{Gas chromatography-mass spectrometry (GC-MS)}

GC-MS used for the analysis of mixture of compounds. The Clarus $680 \mathrm{GC}$ was used in the analysis employed a fused silica column, packed with Elite-5MS (5\% biphenyl $95 \%$ dimethylpolysiloxane, $30 \mathrm{~m} \times 0.25 \mathrm{~mm} \mathrm{ID} \times 250 \mu \mathrm{m} \mathrm{df}$ ) and the components were separated using Helium as carrier gas at a constant flow of $1 \mathrm{ml} / \mathrm{min}$. The injector temperature was set at $260^{\circ} \mathrm{C}$ during the chromatographic run. The $1 \mu \mathrm{L}$ of extract sample injected into the instrument the oven temperature was as follows: $60{ }^{\circ} \mathrm{C}(2 \mathrm{~min})$; followed by $300{ }^{\circ} \mathrm{C}$ at the rate of $10{ }^{\circ} \mathrm{C} \mathrm{min}{ }^{-1}$; and $300{ }^{\circ} \mathrm{C}$, where it was held for $6 \mathrm{~min}$. The mass detector conditions were: transfer line temperature $240{ }^{\circ} \mathrm{C}$; ion source temperature $240{ }^{\circ} \mathrm{C}$; and ionization mode electron impact at $70 \mathrm{eV}$, a scan time 0.2 sec and scan interval of $0.1 \mathrm{sec}$. The fragments from 40 to $600 \mathrm{Da}$. The spectrums of the components were compared with the database of spectrum of known components stored in the GC-MS NIST (2008) library.

\subsection{Corrosion Inhibition Studies}

\section{Sample preparation}

Mild steels of the composition by weight percent; $0.039 \%$ $\mathrm{P} ; 0.06 \% \mathrm{Si} ; 0.55 \% \mathrm{Mn} ; 0.205 \% \mathrm{C}$; Fe balance, was used for this study. Each mild steel specimen was polished using grit silicon carbide sheets in range from 120, 200, 400, 600, 800, 1000 and 1200 Grades. Polished sample is rinsed with double distilled water and acetone. Then dried at room temperature and used for studies.

\section{Weight Loss Method}

Mild Steel Specimens of following Dimensions $3 \mathrm{~cm} * 2.5 \mathrm{~cm} * 0.5 \mathrm{~cm}$ were weighed initially. Mild steel specimens were hanged into the $1 \mathrm{M} \mathrm{HCl}$ solution in the absence of inhibitor and in the presence of inhibitor at different concentrations of $0.03,0.07,0.1,0.25 \%(\mathrm{gm} / \mathrm{ml})$. Mild steel specimens are immersed in the solutions at room temperature. After 12 hours of immersion, the specimens are removed and cleaned with distilled water and dried at room temperature. The final weight of the mild steel was recoded and repeated for a set of values.

Inhibition Efficiency is calculated using the below formula

Where,

$\mathrm{W}_{0}=$ Weight loss without inhibitor

$\mathrm{W}_{\mathrm{i}}=$ Weight loss with inhibitor at i concentration.

\section{Electrochemical Studies}

Electrochemical studies were carried out using Advanced corrosion measurement instrumen. The three electrode setup of mild steel $1 \mathrm{~cm} * 1 \mathrm{~cm} * 0.5 \mathrm{~cm}$ as working electrode which is connected to anode, Platinum as counter electrode connected to cathode and a reference electrode $\mathrm{Ag} / \mathrm{AgCl}$ were used.

\section{Electrochemical Impedance Spectroscopy (EIS)}

EIS measurements were carried using out at with frequency ranges from 100000 to $0.1 \mathrm{~Hz}$ at amplitude of $10 \mathrm{mV}$ and scan rate of 10 points per decade. The results were represented in Nyquist diagrams and the charge transfer resistance $\left(R_{c t}\right)$ value were obtained by fitting with the electrical equivalent circuit of the system.

Inhibition Efficiency is calculated using the below formula

Where,

$$
\operatorname{IE}(\%)=\left(\mathrm{R}_{\mathrm{ct}(\mathrm{i})}-\mathrm{R}_{\mathrm{ct}(0)}\right) / \mathrm{R}_{\mathrm{ct}(\mathrm{i})} * 100
$$

$\mathrm{R}_{\mathrm{ct} \text { (i) }}=$ Charge Transfer Resistance of mild steel with inhibitor at i concentration.

$\mathrm{R}_{\mathrm{ct}(0)}=$ Charge Transfer Resistance of mild steel without inhibitor.

In understanding the Nyquist Plots, Impedance is a measure of the ability of a circuit to resist the flow of electrical current. Whenever the phase shift is zero impedance is equal to resistance.

$$
Z=\frac{E}{I}=Z_{0} \exp (i \phi)=Z_{0}(\cos \phi+i \sin \phi)
$$




\section{International Journal of Science and Research (IJSR) \\ ISSN (Online): 2319-7064}

Index Copernicus Value (2015): 78.96 | Impact Factor (2015): 6.391

Impedance is a measure of resistance of flow of current. Nyquist plot is plotted between the real and imaginary parts of impedance, where $\square \square$ is the frequency.

\section{Potentiodynamic Polarisation Measurement (TAFEL)}

The TAFEL polarisation curves were obtained by scanning the electrode potential from $-300 \mathrm{mV}$ to $300 \mathrm{mV}$ with respect to $E_{\text {corr }}$ with a scanning rate of $1 \mathrm{mVs}-1$. The linear segments of the anodic and cathodic curves were extrapolated to obtain the corrosion current densities $I_{\text {corr }}$. The IE $\%$ can be calculated using the formula:

$$
\mathrm{IE}(\%)=\left(\mathrm{I}_{\text {corr (0) }}-\mathrm{I}_{\text {Corr (i) }}\right) / \mathrm{I}_{\text {Corr (0) }} * 100
$$

$\mathrm{I}_{\text {corr }(0)}=$ Corrosion Current Density of mild steel without inhibitor

$\mathrm{I}_{\text {Corr (i) }}=$ Corrosion current density of mild steel with inhibitor.

Scanning Electron Microscope (Carl Zeiss Supra-55 SEM) was used to monitor the surface morphological changes. The mild steel $1 \mathrm{~cm}^{*} 1 \mathrm{~cm}^{*} 0.5 \mathrm{~cm}$ were immersed for 1 hours at room temperature in $1 \mathrm{M} \mathrm{HCl}$ solution for control (absence of inhibitor) and inhibitors in their respective concentrations that exhibited the highest IE for weight loss method. Mild steel plates were then rinsed with distilled water and allowed to dry at room temperature and analysed for SEM.

\section{Results and Discussion}

\subsection{Analysis of Chemical Constituents of Banana Peel (PE)}

\section{Fourier Transform Infrared Spectroscopy (FTIR)}

The chemical constituents that contribute to the corrosion inhibition have specific functional groups. The IR spectra of ethanolic extract of banana peel were shown in the Figure 2. The inhibitors were analysed with the FTIR to identify the functional groups present in the extract. The Absorption band from 3500 to $3000 \mathrm{~cm}^{-1} \mathrm{BE}$ indicates the presence of The following functional groups $-\mathrm{O}-\mathrm{H}$, The peak from 3000 to $2750 \mathrm{~cm}^{-1}$ BE Indicates the presence of $-\mathrm{C}-\mathrm{H}$ stretching and 1500 to $1000 \mathrm{~cm}^{-1}$ peaks confirms the presence of $\mathrm{C}-\mathrm{N}$, $\mathrm{N}-\mathrm{O}, \mathrm{C}-\mathrm{O}$ groups. The major peaks present in banana peel by FTIR analysis was the presence of $-\mathrm{O}-\mathrm{H}$ Groups, $-\mathrm{C}-\mathrm{H}$ stretching's, functional groups with $\mathrm{C}-\mathrm{O}$ Bonds.

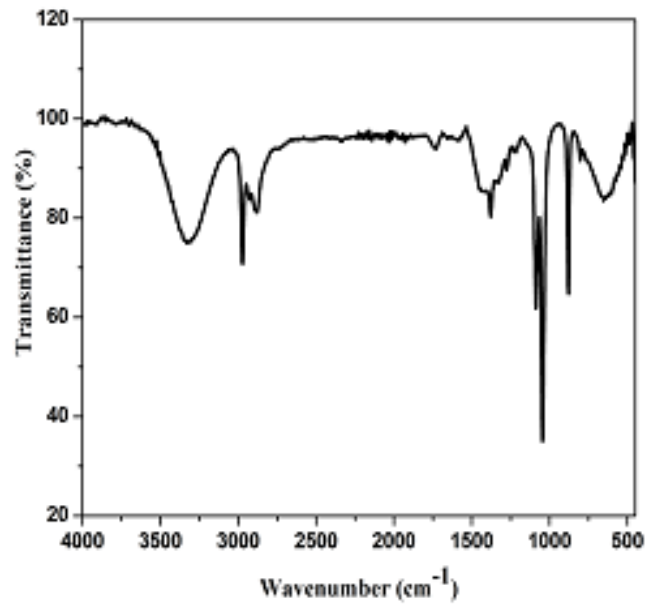

Figure 2: FTIR Analysis of banana Peel Extract

Gas Chromatography -Mass Spectrometry (GC-MS)
The chemical constiuents present in the banana peel was analysed by GC-MS. The chemical constiuents present in the ethanolic extracts were summarized in the Table 1 . The compounds present in the ethanolic extract shows presence of heterocyclic groups and double bond groups in their structures which highly related to the pervious IR spectra results. These heterocyclic groups and phenolic compounds where responsible for the adsorption of the organic molecules present in the banana peel extract. These heterocyclic ,phenolic and unsaturated groups which acts as a active site for the binding of the inhibitor molecule to the metal surface.

Table 1: Chemical Compounds Present In banana Peel

\begin{tabular}{|l|c|c|}
\hline No. & Structure of Compound & $\begin{array}{c}\text { Common Name or IUPAC } \\
\text { Name }\end{array}$ \\
\hline 1. & & $\begin{array}{c}\text { Furfural } \\
\text { 2,5-dihyroxy-6-methyl-2H- } \\
\text { pyran-4(3H)-one }\end{array}$ \\
\hline 3. & \\
\hline 4. & & $\begin{array}{c}\text { 5-(hydroxymethyl)furan-2- } \\
\text { carbaldehyde }\end{array}$ \\
\hline 5. & 0 & Benzophenon \\
\hline
\end{tabular}

\subsection{Corrosion Studies of Banana Peel}

\section{Weight Loss Method}

The weight loss method is a form of gravimetric method of studying the anti-corrosion activity of the inhibitors. The results obtained for varying concentrations of the inhibitors are depicted in Table. 2. Inhibition efficiency also calculated using equation.1. and the corresponding values were tabulated in the Table.3.

Table 2: Weight Loss Difference for banana Peel

\begin{tabular}{|c|c|c|c|}
\hline $\begin{array}{c}\text { Specimen. } \\
\text { No. }\end{array}$ & $\begin{array}{c}\text { Initial } \\
\text { Weight }\end{array}$ & $\begin{array}{c}\text { Final } \\
\text { Weight }\end{array}$ & $\begin{array}{c}\text { Weight } \\
\text { Difference }\end{array}$ \\
\hline Weight (\%) & $\mathrm{W}_{1}$ gm & $\mathrm{W}_{2}$ gm & $\mathrm{W}_{1}-\mathrm{W}_{2}$ gm \\
\hline Bare & 13.6281 & 13.5287 & 0.0994 \\
\hline 0.03 & 14.9742 & 14.9433 & 0.0309 \\
\hline 0.07 & 15.2490 & 15.2286 & 0.0204 \\
\hline 0.1 & 14.1399 & 14.1207 & 0.0192 \\
\hline 0.25 & 14.2107 & 14.1954 & 0.0153 \\
\hline
\end{tabular}

Table 3: Inhibition Efficiency of banana Peel

\begin{tabular}{|c|c|c|}
\hline Inhibitor & Conc. of Inhibitor & Inhibitor Efficiency \\
\hline \multirow{4}{*}{$\begin{array}{c}\text { Banana } \\
\text { Peel }\end{array}$} & Weight $(\%)$ & $\%$ \\
\cline { 2 - 3 } & 0.03 & 68.90 \\
\cline { 2 - 3 } & 0.07 & 79.40 \\
\cline { 2 - 3 } & 0.1 & 80.68 \\
\cline { 2 - 3 } & 0.25 & 84.60 \\
\hline
\end{tabular}

As you seen from the Table .2. and table.3. The loss in weight was decreases with increase in the concentration of inhibitor. This confirms that the increase in concentration of inhibitor leads to more protection metal surface from the 


\section{International Journal of Science and Research (IJSR) \\ ISSN (Online): 2319-7064}

Index Copernicus Value (2015): 78.96 | Impact Factor (2015): 6.391

acidic attack. The IE \% Increases with increase in concentration of the inhibitor BE. This is due to the adsorption of inhibitors molecules on the metal surface and thus increases the degree of surface coverage. The increased coverage will protect the metal from the corrosion process as it creates a separation of the metal surface from the acid medium. The efficiency of $84.60 \%$ at $2.5 \%(\mathrm{gm} / \mathrm{ml})$ were shown for banana peel extract.

\subsection{Electrochemical Studies}

\section{Electrochemical Impedance Spectroscopy (EIS)}

EIS results obtained are given as Nyquist plots were shown in Figure 2. EIS can also be represented as Bode and phase angle Plots $(\log |\mathbf{Z}|$ vs $\log$ Frequency) as shown in Figure.3. $\& 4$.

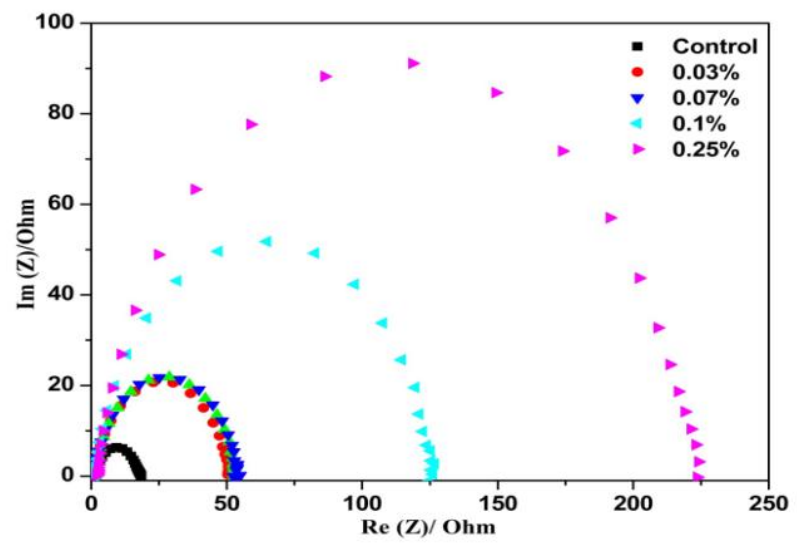

Figure 2: Nyquist plots

Table 3: Corrosion efficiency of banana Peel Using EIS Analysis

\begin{tabular}{|c|c|c|c|}
\hline Sp. No. & $\begin{array}{c}\mathrm{R}_{\mathrm{ct}} \\
(\text { Ohms })\end{array}$ & $\begin{array}{c}\text { Surface } \\
\text { Coverage }\end{array}$ & $\begin{array}{c}\text { Efficiency } \\
(\%)\end{array}$ \\
\hline Control & 18.64 & & \\
\hline 0.03 & 47.79 & 0.62 & 62 \\
\hline 0.07 & 53.09 & 0.64 & 64 \\
\hline 0.1 & 124.5 & 0.85 & 85 \\
\hline 0.25 & 220.9 & 0.91 & 91 \\
\hline
\end{tabular}

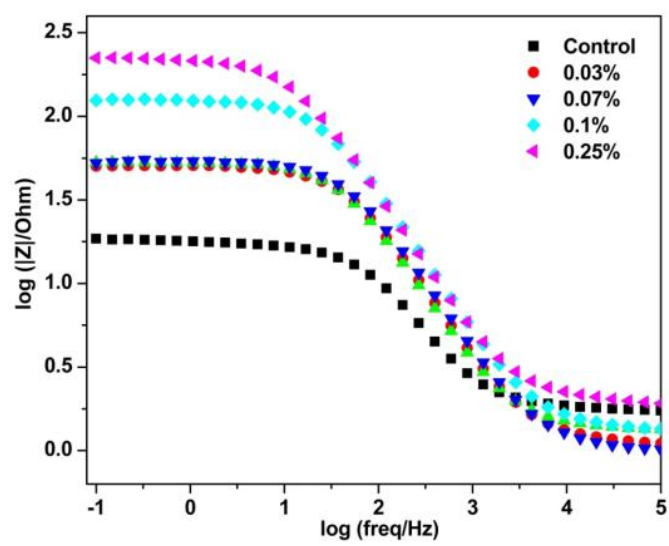

Figure 3: Bode plots

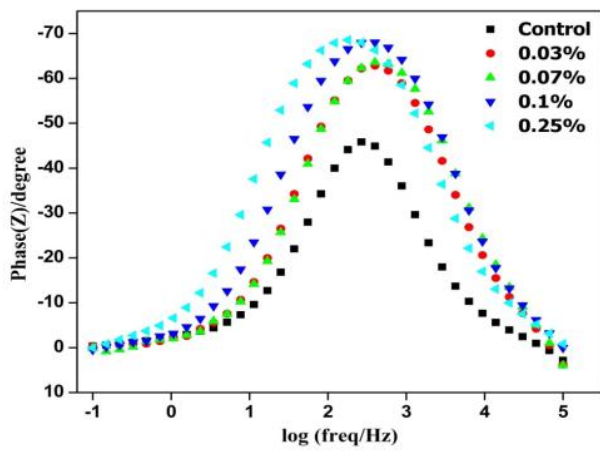

Figure 4: Phase angle plots

The Nyquist Plot of mild steel in the absence and presence of inhibitor banana peel at different concentrations are shown in Figure 2. It is observed that with increase in concentration of inhibitor, the diameter of loop is increasing. The diameter of the loop indicates the resistance towards the flow of electrons. The increase in diameter of loop with concentration implies increase in resistance $\left(R_{c t}\right)$ towards flow of electrons. This is due to the formation of the inhibitor as a protective film on the metal surface, which acts as a potential barrier against corrosive environment. The bode and phase angle plots (Figure $3 \& 4$ ) also agreeing this concepts by increasing in their resistance and angle values with respect to frequency applied to done the experiment at different concentrations. The inhibition efficiency of the inhibitors with various concentrations were calculated from $\mathrm{R}_{\mathrm{ct}}$ and shown in the Table. It was observed that the inhibition efficiency shows increasing trend with concentration of inhibitor and the inhibition efficiency of $91 \%$ was found to be at concentration $(0.25 \%)$. These results showed that the banana peel extract acts as an effective corrosion inhibitor.

\section{TAFEL studies}

The potentiodynamic polarisation measurement allows for the study of anticorrosion behaviour via anodic and cathodic polarisations. The measurements were recorded and analysed as TAFEL plots as shown in Figure 5 with the electrochemical parameters presented in Table $5 \mathrm{E}_{\text {corr }}$ refers to the corrosion potential, $\mathrm{I}_{\text {corr }}$ refers to the corrosion current density, $\beta \mathrm{a}$ and $\beta \mathrm{c}$ refer to the anodic and cathodic TAFEL slopes, respectively, of the polarisation curves.

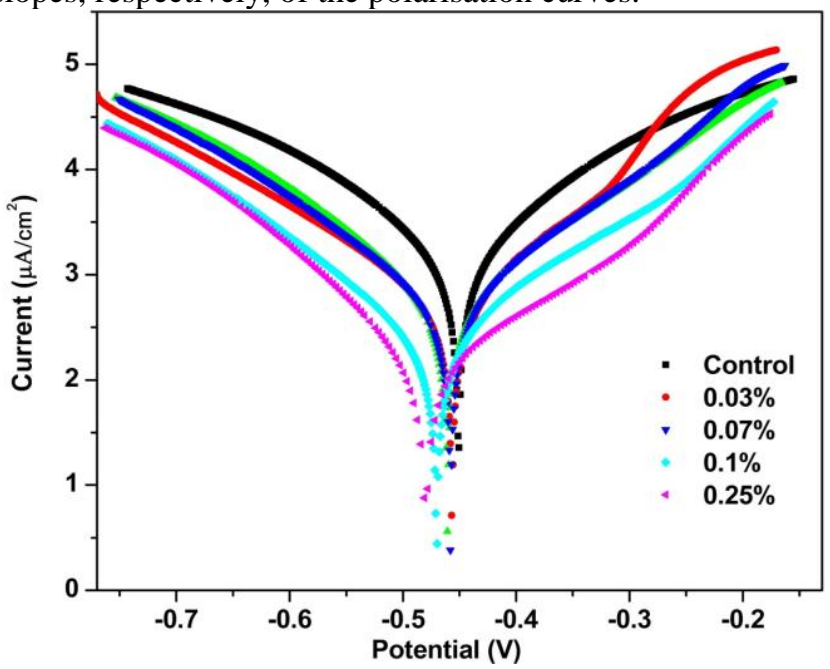

Figure 5: TAFEL plots at different concentration. 


\section{International Journal of Science and Research (IJSR) \\ ISSN (Online): 2319-7064}

Index Copernicus Value (2015): 78.96 | Impact Factor (2015): 6.391

Table 5: Corrosion efficiency of banana Peel Using TAFEL studies

\begin{tabular}{|c|c|c|c|c|c|}
\hline Sp. No. & $\mathrm{E}_{\text {Corr. }}$ & $\beta \mathrm{a}$ & $\beta \mathrm{c}$ & $\mathrm{I}_{\text {Corr. }}$ & Efficiency \\
\hline$\%$ & $\mathrm{mV}$ & $\mathrm{mV}$ & $\mathrm{mV}$ & $\mathrm{mV} / \mathrm{cm}^{2}$ & $\%$ \\
\hline Control & -451 & 156.1 & 167.8 & 1908.679 & - \\
\hline 0.03 & -434 & 88.2 & 154.2 & 381.926 & 80.03 \\
\hline 0.07 & -459 & 133.9 & 136.7 & 509.921 & 73.32 \\
\hline 0.1 & -479 & 160.7 & 126.7 & 245.468 & 86.68 \\
\hline 0.25 & -467 & 147.4 & 116.4 & 135.493 & 92.92 \\
\hline
\end{tabular}

The $\mathrm{I}_{\text {Corr. }}$ Value decreases with increase in concentration of inhibitor PE \& OE. The decrease in $\mathrm{I}_{\text {Corr. }}$ Value indicates that decrease in flow of electrons, i.e., Corrosion is supressed on the specimen. The flow Of electrons is inhibited with increase in concentration of inhibitor banana peel, Which is due to the adsorption of inhibitor molecules on the metal surface. An Inhibitor is classified as cathodic or anodic with the $\mathrm{E}_{\mathrm{Corr}}$ value displacement from the control is greater than $85 \mathrm{mV}$. If the value is less than $85 \mathrm{mV}$, then the inhibitor is considered to be mixed type inhibitor. Our

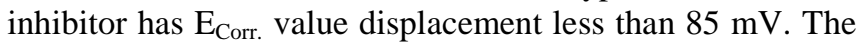
significance of $\beta \mathrm{a}$ and $\beta \mathrm{c}$ Value, We can see that $\beta \mathrm{a}$ is greater than $\beta c$ this indicates that extract has high cathodic current density than the anodic part, Though some values have $\beta c$ is greater than $\beta \mathrm{a}$ But, differ in very low value indicates that the inhibitor used is inhibiting the corrosion and predominantly inhibiting cathodic reaction. The result implies that the inhibitor used is mixed inhibitor and effective towards cathodic inhibition. The inhibition efficiency was calculated from the $\mathrm{I}_{\text {Corr. }}$ Value. The Maximum Efficiency was found to be $92.92 \%$ at $0.25 \%$ ( $\mathrm{gm} / \mathrm{ml})$.

\section{Scanning Electron Microscopy (SEM)}

Surface morphology of polished mild steel, mild steel exposed to $1 \mathrm{M} \mathrm{HCl}$ Solution in the absence of inhibitor (Bare), mild steel exposed to $1 \mathrm{M} \mathrm{HCl}$ Solution in the presence of inhibitor at $2.5 \%(\mathrm{gm} / \mathrm{ml})$ is recorded using scanning electron microscope. The results of the samples were shown in the Figure. 6, 7 and 8. The SEM results shows that the absence of inhibitor shows more oxidised product in the metal surface with more damages. Where in the presence of there is no corrosion takes place in the surface due to the binding of inhibitor molecules (banana peel extract) to the meatl surface which also visible in the SEM images. The mechanism of the adsorption is further understood by fitting the weight loss method, EIS analysis and potentiodynamic polarisation measurements into adsorption isotherm models. The fit of the adsorption isotherm models are determined by the closeness of linear correlation coefficient $\left(\mathrm{R}^{2}\right)$ value to unity. The best fitted models with $\mathrm{R}^{2}$ closest to unity were then picked to describe the mechanism of adsorption.

\section{SEM Images}

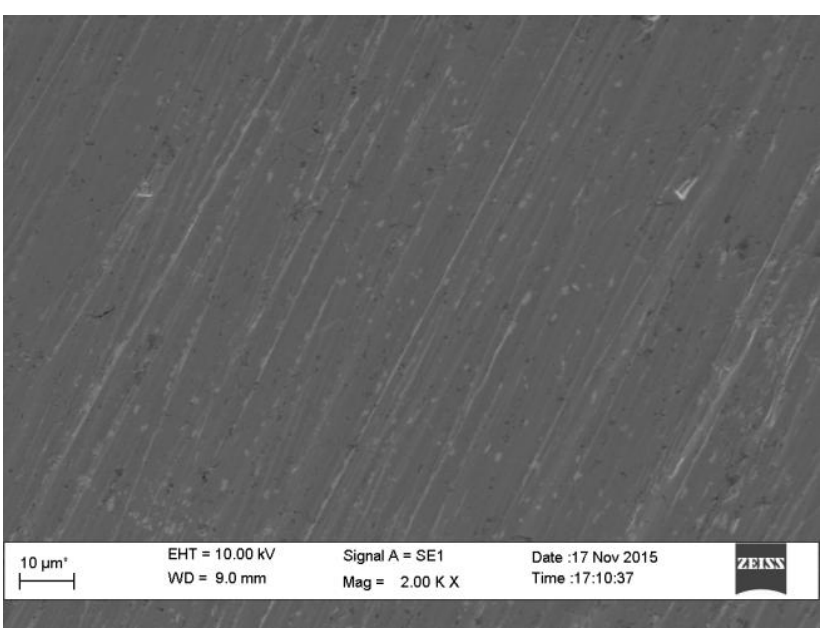

Figure 6: Before immersion in acid

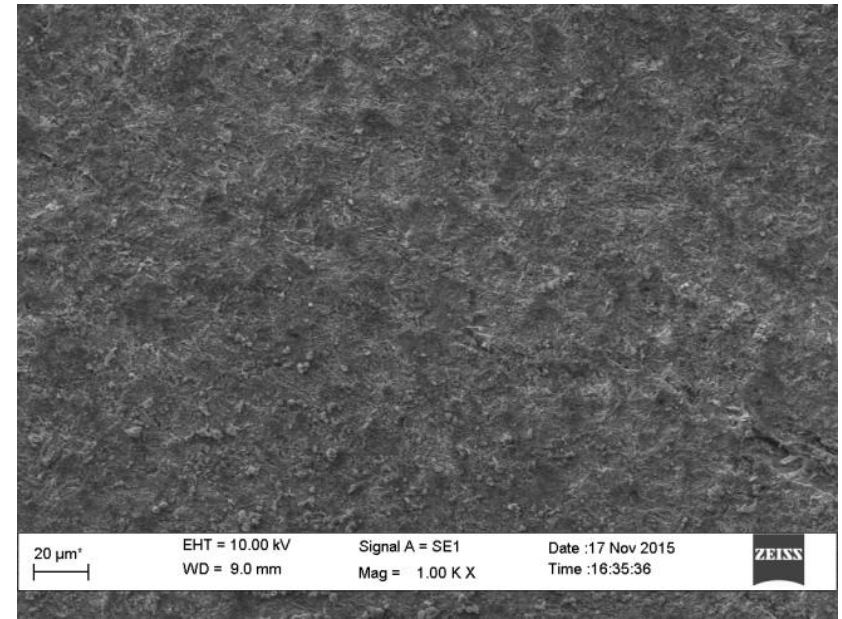

Figure 7: After immersion in acid without inhibitor

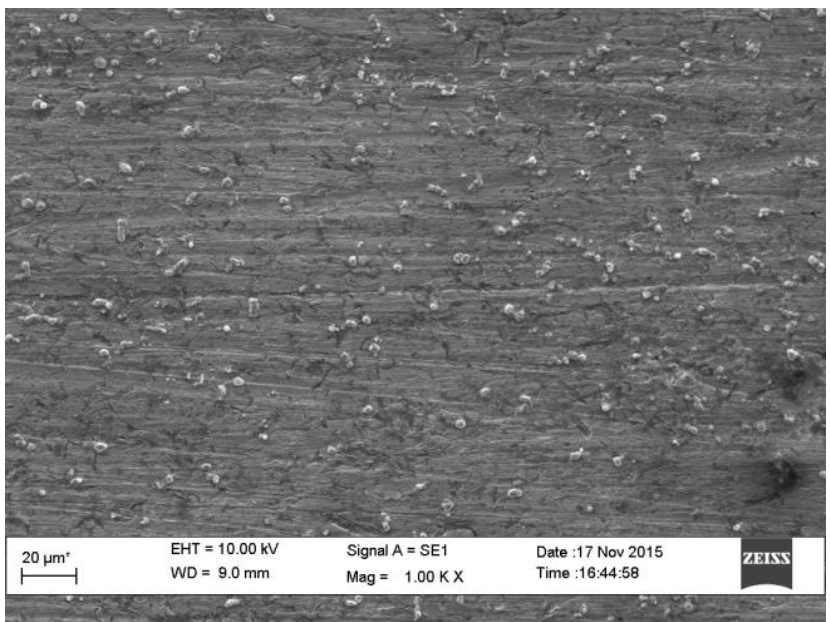

Figure 8: After immersion in acid with inhibitor.

\section{Adsorption Isotherm}

\section{Langmuir Adsorption Isotherm Model}

The Langmuir adsorption isotherm model assumes that the molecules adsorbed only occupies one site and does not interact with other molecules.

Where,

$$
\mathrm{C} / \boldsymbol{\Theta}=\mathbf{1} / \mathrm{K}_{\mathrm{ads}}+\mathrm{C}
$$

$\mathrm{C}=$ inhibitor concentration in $\mathrm{g} \mathrm{L}-1$

$\Theta=$ surface coverage or fraction of inhibition efficiency 


\section{International Journal of Science and Research (IJSR) \\ ISSN (Online): 2319-7064}

Index Copernicus Value (2015): 78.96 | Impact Factor (2015): 6.391

Kads $=$ adsorption equilibrium constant

The Kads is reported to be related to the Gibbs free energy at a single temperature. The value of Kads obtained can be used to calculate the Gibbs free energy via the equation:

Where,

$$
\Delta \mathbf{G}_{\mathrm{ads}}=-\mathbf{R T} \ln \left(\mathrm{K}_{\mathrm{ads}} * \mathbf{A}\right)
$$

$\Delta \mathrm{G}_{\mathrm{ads}}=$ change in Gibbs free energy

Kads $=$ adsorption equilibrium constant

$\mathrm{R}=$ universal gas constant $(8.314 \mathrm{~J} \mathrm{~K}-1 \mathrm{~mol}-1)$

$\mathrm{T}=$ absolute temperature $(300 \mathrm{~K})$

$\mathrm{A}=$ density of water $(1000 \mathrm{~g} \mathrm{~L}-1)$

A Graph is plotted between $\mathbf{C} / \boldsymbol{\theta}$ and $\mathbf{C}$ using $\boldsymbol{\Theta}$ (Surface Coverage) Values of weight loss measurements, EIS and TAFEL.

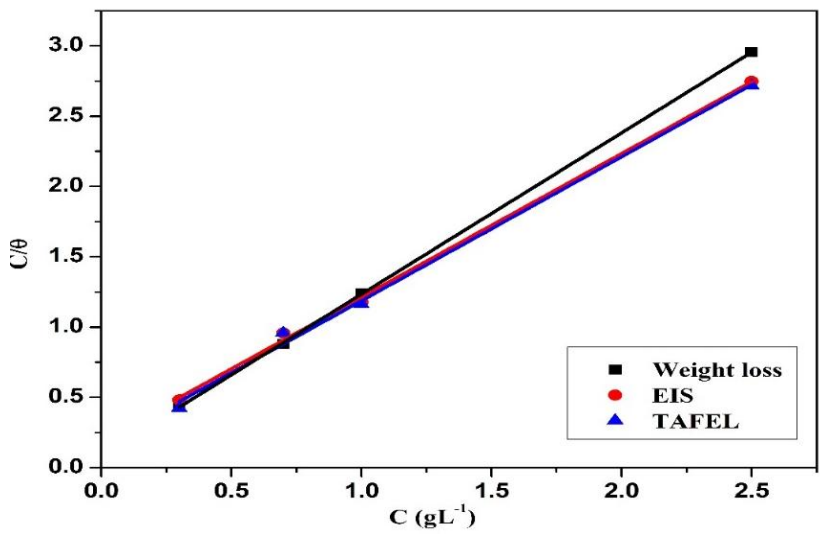

Figure 9: Langmuir Adsorption Isotherm plot for Banana Peel

Table 6: $\mathrm{K}_{\mathrm{ads}}$ and $\Delta \mathrm{G}_{\mathrm{ads}}$ Obtained Using Langmuir Adsorption Isotherm.

\begin{tabular}{|c|c|c|c|c|c|}
\hline Method & Slope & Y-Intercept & $\mathrm{R}^{2}$ & $\begin{array}{c}\mathrm{K}_{\text {ads }} \\
\left(\mathrm{L} \mathrm{g}^{-1}\right)\end{array}$ & $\begin{array}{c}\Delta \mathrm{G}_{\text {ads }} \\
\left(\mathrm{kJ} \mathrm{mol}^{-1}\right)\end{array}$ \\
\hline Weight Loss & 1.1472 & 0.08687 & 0.9995 & 11.52 & -23.32 \\
\hline EIS & 1.0206 & 0.1928 & 0.9978 & 5.186 & -21.33 \\
\hline TAFEL & 1.0239 & 0.1633 & 0.9954 & 6.123 & -21.74 \\
\hline
\end{tabular}

Temkin adsorption isotherm assumes molecular interaction between adsorbed molecules.

$$
\operatorname{Exp}(-2 a \Theta)=\operatorname{Kads} C
$$

The above equation can be represented as

$$
-2 \mathrm{aO}=\ln \mathrm{Kads}+\ln \mathrm{C}
$$

Where,

$\mathrm{C}=$ inhibitor concentration in $\mathrm{g} \mathrm{L}-1$

$\Theta=$ surface coverage or fraction of inhibition efficiency

Kads = adsorption equilibrium constant

$\mathrm{a}=$ parameter of molecules interaction and surface heterogeneity

The Kads is reported to be related to the Gibbs free energy at a single temperature. The value of Kads obtained can be used to calculate the Gibbs free energy via the equation:

$$
\Delta G_{\mathrm{ads}}=-\mathbf{R T} \ln \left(\mathrm{K}_{\mathrm{ads}} * \mathrm{~A}\right)
$$

Where,

$\Delta \mathrm{G}_{\mathrm{ads}}=$ change in Gibbs free energy

Kads $=$ adsorption equilibrium constant

$\mathrm{R}=$ universal gas constant (8.314 J K-1 mol-1)
$\mathrm{T}=$ absolute temperature $(300 \mathrm{~K})$

$\mathrm{A}=$ density of water $(1000 \mathrm{~g} \mathrm{~L}-1)$

A Graph is plotted between $\Theta$ and $\ln \mathrm{C}$ using $\Theta$ (Surface Coverage) Values of weight loss measurements, EIS and

TAFEL.

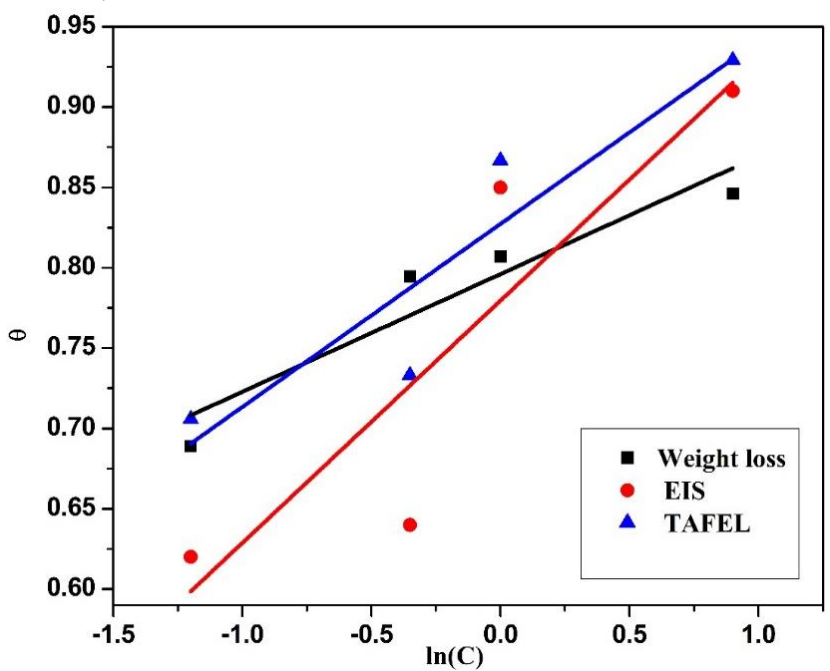

Figure 10: Temkin Adsorption Isotherm for banana Peel

Table 7: $\mathrm{K}_{\mathrm{ads}}$ and $\Delta \mathrm{G}_{\mathrm{ads}}$ Obtained Using Temkin Adsorption Isotherm

\begin{tabular}{|c|c|c|c|c|c|}
\hline Method & Slope & Y-Intercept & $\mathrm{R}^{2}$ & $\begin{array}{c}\ln \mathrm{K}_{\mathrm{ads}} \\
\left(\mathrm{L} \mathrm{g}^{-1}\right)\end{array}$ & $\begin{array}{c}\Delta \mathrm{Gads} \\
\left(\mathrm{kJ} \mathrm{mol}^{-1}\right)\end{array}$ \\
\hline Weight Loss & 0.0732 & 0.7960 & 0.8527 & 10.8 & -44.17 \\
\hline EIS & 0.1507 & 0.7795 & 0.6981 & 5.1 & -29.93 \\
\hline TAFEL & 0.1139 & 0.8272 & 0.7920 & 7.2 & -35.16 \\
\hline
\end{tabular}

From both the Langmuir and Temkin Adsorption Isotherms for banana peel, The best fitted model is determined using $\mathrm{R}^{2}$ Values from the tabulation. Langmuir Adsorption Isotherm model can be used in determining the type of adsorption. The type of adsorption is determined by $\Delta \mathrm{G}_{\mathrm{ads}}$ values, for values closer to $-40 \mathrm{~kJ} \mathrm{~mol}^{-1}$ the adsorption leans towards chemisorption while for values closer to $-20 \mathrm{~kJ}$ mol 1 , the adsorption leans towards physisorption. The chemisorption phenomenon indicates the occurrence of sharing of electrons or transferring of organic molecule charges with the metal surface while the physisorption phenomenon is attributed to electrostatic interactions between the charged metal and charged molecules. The type of Adsorption occurring is physisorption as the values in Langmuir isotherm of banana peel ranging from -21.33 to $23.33-20 \mathrm{~kJ} \mathrm{~mol}^{-1}$. Both the values are closer to $-20 \mathrm{~kJ}$ $\mathrm{mol}^{-1}$.

\section{Mechanism of Corrosion Inhibition}

Ethanol extract of banana peels has various organic compounds containing heteroatom and found out aliphatic compounds without heteroatom as well which have been compared with library search NIST-2008 form GC-MS data. The adsorption mechanism of extract was derived by Langmuir isotherm. We found that from the experimental results, the interaction between metal and extract is physical contact. Heterocyclic and heteroatom containing aliphatic compounds usually participate in electron transfer adsorption via their lone pair electrons. The free energy change will be higher in electron transfer adsorption than weak electrostatic force like Vander walls force. Weak electrostatic force will be formed between non polar 


\section{International Journal of Science and Research (IJSR) \\ ISSN (Online): 2319-7064 \\ Index Copernicus Value (2015): 78.96 | Impact Factor (2015): 6.391}

compound and polarized surface. Our calculated energy of this experiment meets the weak electrostatic attraction (physisorption). So we conclude here as, the aliphatic organic compounds are predominantly responsible for corrosion inhibition.

\section{Conclusions}

1) Weight Loss studies for banana peel concludes that inhibition efficiency increases with increase in concentration of Inhibitor due to the increase in surface coverage of the inhibitor on the specimen.

2) Banana peel acts as an effective corrosion inhibitor, Nyquist Plot concludes that the charge transfer resistance (resist to flow of electrons) increases with increase in concentration of the Inhibitor.

3) Potentiodynamic polarization studies concludes that ethanolic extract of banana peel is a mixed type inhibitor with predominating cathodic inhibition.

4) The above results were confirmed using scanning electron microscopy images.

5) Adsorption Isotherms plotted confirmed that the type of adsorption occurring on the metal surface is physisorption.

6) Above results conclude that the ethanol extract of the banana peel was an effective corrosion inhibitor for industrial applications.

\section{References}

[1] Camila G. Dariva and Alexandre F. Galio Corrosion Inhibitors - Principles, Mechanisms and Applications, Http://Dx.Doi.Org/10.5772/57255.

[2] L.M. Rivera-Grau, M. Casales, I. Regla, D.M. OrtegaToledo, J.A. Ascencio-Gutierrez, J. Porcayo-Calderon, L. Martinez-Gomez, Effect Of Organic Corrosion Inhibitors On The Corrosion Performance Of 1018 Carbon Steel In 3\% Nacl Solution Int. J. Electrochem. Sci., 8 (2013) 2491 - 2503.

[3] J. S. Cai, C. C. Chen, J. Z. Liu And J. P. Liu, Influence Of Organic Inhibitor On Corrosion Resistance of Steel In Simulated Concrete Pore Solution, 4th International Conference On The Durability Of Concrete Structures 24-26 July 2014, Purdue University, West Lafayette, IN, USA.

[4] Ghulamullah Khan, Kazi Md. Salim Newaz, Wan Jefrey Basirun, Hapipah Binti Mohd Ali, Fadhil Lafta Faraj, Ghulam Mustafa Khan, Application Of Natural Product Extracts As Green Corrosion Inhibitors For Metals And Alloys In Acid Pickling Processes, Int. J. Electrochem. Sci., 10 (2015) 6120 - 6134.

[5] Shyamala Bellur Nagarajaiah and Jamuna Prakash, Chemical composition and antioxidant potential of peels from three varieties of banana, As. J. Food Ag-Ind. 2011, 4(01), 31-46.

[6] Ramakrishnan baskar, selvaraj shrisakthi, babu sathyapriya, radhakrishnan shyampriya, radhakrishnan nithya, palanisamy poongodi, Antioxidant potential of peel extracts of banana varieties (musa sapientum), food and nutrition sciences, 2011, 2, 1128-1133.

[7] K. P. Sampath Kumar, Debjit Bhowmik, S. Duraivel, M. Umadevi, Traditional and Medicinal Uses of
Banana, Journal of Pharmacognosy and Phytochemistry, Vol. 1 No. 32012.

[8] Ehiowemwenguan, G. Emoghene, A. O.and Inetianbor, J.E., Antibacterial and phytochemical analysis of Banana fruit peel, IOSR Journal Of Pharmacy, Volume 4, Issue 8 (August 2014), PP. 18-25.

[9] L. Y. S. Helen, A. A. Rahim, B. Saad, M. I. Saleh, P. Bothi Raja , Aquilaria Crassna Leaves Extracts - a Green Corrosion Inhibitor for Mild Steel in $1 \mathrm{M} \mathrm{HCl}$ Medium, Int. J. Electrochem. Sci., 9 (2014) 830 - 846.

[10] S. Noyel Victoria, Rohith Prasad, R. Manivannan, Psidium Guajava Leaf Extract as Green Corrosion Inhibitor for Mild steel in Phosphoric Acid, Int. J. Electrochem. Sci., 10 (2015) 2220 - 2238.

[11] Aprael S. Yaro, Anees A. Khadom, Rafal K. Wael, Apricot Juice As Green Corrosion Inhibitor Of Mild Steel In Phosphoric Acid, Alexandria Engineering Journal Volume 52, Issue 1, March 2013, Pages 129135.

[12] S. Leelavathi, R. Rajalakshmi, Dodonaea viscosa (L.) Leaves extract as acid Corrosion inhibitor for mild Steel - A Green approach, J. Mater.Environ. Sci. 4(5) (2013) 625-638.

[13] C. Maxime , R. Florent, A. Nadine, T. Michel, R. Christophe, L. Mounim, Enhanced corrosion resistance of mild steel in $1 \mathrm{M}$ hydrochloric acid solution by alkaloids extract from Aniba rosaeodora plant:Electrochemical, phytochemical and XPS studies, Electrochim.Acta. 131 (2014) 96-105.

[14] M. Faustin , A. Maciuk , P. Salvin , C. Roos , M. Lebrini , Corrosion inhibition of C38 steel by alkaloids extract of Geissospermum laeve in $1 \mathrm{M}$ hydrochloric acid: Electrochemical and phytochemical studies, Corros. Sci. 92 (2015) 287-300.

[15] A.K. Singh, S. Mohapatra , B. Pani, Corrosion inhibition effect of Aloe Vera gel: Gravimetric and electrochemical study, J. Ind.Eng.Chem. 33 (2016) 288297. 